\title{
MENINGKATKAN KESADARAN MASYARAKAT TERHADAP PENYAKIT KECACINGAN DI BANTARAN SUNGAI CILIWUNG, JAKARTA TIMUR
}

\author{
Dina Atrasina Satriawan¹, Ricky Ravindra Fajar Adi Putra1, Tri Putra Dinata Giri', \\ Brigitta Priscilla Warouw ${ }^{1}$, Nur Endaz Azizah Azis ${ }^{1}$, Alifia Hetifa Rahma ${ }^{1}$ \\ ${ }^{1}$ Indonesia International Institute for Life Sciences \\ dina.satriawan@i31.ac.id, ricky.ravindra@student.i31.ac.id, tri.putra@student.i31.ac.id, \\ brigitta.priscilla@student.i3l.ac.id,nur.endaz@student.i3l.ac.id, alifia.hetifa@student.i3l.ac.id
}

\begin{abstract}
Abstrak
Penyakit kecacingan telah menjadi salah satu masalah kesehatan baik di dunia maupun di Indonesia. Di Jakarta Timur sendiri, prevalensi kecacingan sekurangnya mencapai $2.5 \%$ dan paling banyak menyerang usia balita dan usia sekolah dasar. Angka ini semakin meningkat di daerah dengan jumlah penduduk tinggi dengan sarana dan prasarana sanitasi yang kurang memadai serta tingkat kesadaran terhadap sanitasi yang rendah seperti di beberapa daerah bantaran sungai di Jakarta. Oleh karena itu, kegiatan pengabdian ini bertujuan untuk meningkatkan kesadaran masyarakat di bantaran sungai Ciliwung akan dampak penyakit kecacingan serta cara pencegahannya dengan perilaku hidup bersih sehat (PHBS). Kegiatan ini diselenggarakan oleh 6 mahasiswa pengurus dan 2 dosen penanggung jawab yang bekerja sama dengan sebuah kelompok ibu rumah tangga (IRT) yang tinggal di bantaran sungai Ciliwung dengan cara: (1) koordinasi dengan pemimpin daerah setempat dan kepala kelompok IRT, (2) melaksanakan penyuluhan kecacingan dan PHBS, (3) praktek cuci tangan dengan benar pada kelompok tersebut, serta (4) melakukan evaluasi pra dan pasca pemberian materi kepada para IRT. Hasil kegiatan ini menunjukkan bahwa terdapat peningkatan pengetahuan dan kesadaran kelompok IRT akan penyakit kecacingan dan PHBS setelah kegiatan PKM $(4,96 \pm 2,99)$ dibandingkan sebelum kegiatan $(4,08 \pm 2,56)(p=0,039)$.
\end{abstract}

Kata Kunci : cacingan, Ciliwung, penyuluhan, PHBS, sanitasi

\section{PENDAHULUAN}

Penyakit cacingan atau kecacingan adalah penyakit yang disebabkan oleh infeksi cacing yang berasal dari lingkungan sekitar, baik dari air maupun tanah yang terkontaminasi (WHO, 2017). Terdapat tiga jenis cacing yang paling sering menyebabkan infeksi penyakit ini yaitu, Ascaris lumbricoides (cacing gelang), Trichuris trichiura (cacing 
cambuk), dan Necator americanus atau Ancylostoma duodenale (cacing tambang) (Kumar et al., 2014).

Kementerian Kesehatan (KEMENKES) Indonesia telah melaporkan bahwa prevalensi penyakit kecacingan di Indonesia bervariasi dari $2,5 \%$ hingga $62 \%$ di setiap provinsi dan dapat menjangkit semua kelompok usia. Namun demikian, anak-anak usia di bawah lima tahun dan sekolah dasar menjadi kelompok yang paling rentan (Islamudin, 2018; Novianty, 2018). Bahkan, World Health Organization (WHO) mencatat ada sekitar 62 juta anak Indonesia berisiko tinggi terinfeksi cacing.

Tingginya kasus kecacingan di masyarakat sangat berhubungan dengan faktor-faktor risiko yang meliputi minimnya kebiasaan perilaku hidup bersih dan sehat (PHBS), kurangnya sanitasi lingkungan tempat tinggal, serta rendahnya tingkat pendidikan dan sosial ekonomi (Novianty, Pasaribu, \& Pasaribu, 2018). Kecacingan pada anak, khususnya, dapat diakibatkan oleh kurangnya kebersihan perorangan orang tua atau pengasuh sehingga berdampak buruk pada perilaku hidup bersih pada anak (Novianty, Pasaribu, \& Pasaribu, 2018).

Meskipun kasus penyakit kecacingan cenderung lebih banyak terjadi di daerah pedesaan, di beberapa area kota di Jakarta, terutama di sekitar bantaran sungai, kasus kecacingan masih sering ditemukan (Winita \& Astuti, 2012). Di daerah Kramat Jati, Jakarta Timur, masih banyak terdapat masyarakat yang hidup sekitar bantaran sungai Ciliwung. Tidak semua lapisan tanah di daerah pemukiman bantaran sungai telah tertutupi oleh aspal, sehingga faktor risiko perkembangbiakan cacing masih cukup tinggi (Luo et al., 2019; Ribas et al., 2017). Sungai Ciliwung juga telah dilaporkan sebagai sungai yang memiliki kadar polutan tinggi seperti timbal berat serta limbah biologis (Purba et al., 2018) dan terkontaminasinya tanah seringkali terjadi akibat meluapnya air dari aliran sungai (Surwani et al., 1991).

Untuk mencegah penyakit kecacingan di daerah bantaran sungai Ciliwung, maka edukasi dini mengenai dampak, faktor risiko, serta pencegahan penyakit kecacingan sangat diperlukan. Edukasi ini terutama perlu ditujukan kepada kelompok ibu rumah tangga (IRT) mengingat bahwa ibu merupakan panutan sekaligus pengajar paling berpengaruh di keluarga untuk anak-anaknya, apalagi anak-anak merupakan kelompok paling berisiko terkena penyakit kecacingan.

Maka dari itu, kegiatan pengabdian ini bertujuan untuk mengedukasi serta meningkatkan kesadaran masyarakat, khususnya kelompok IRT, akan dampak penyakit kecacingan serta cara mencegahnya melalui kegiatan penyuluhan serta praktek perilaku hidup bersih sehat (PHBS). Pelaksanaan kegiatan pengabdian ini diharapkan membawa manfaat berupa perubahan perilaku pada kelompok IRT sehingga dapat mengurangi dampak kecacingan serta memutus rantai penularan pada anak-anak, khususnya di daerah bantaran sungai Ciliwung, Kramat Jati, Jakarta Timur.

\section{METODE}

Kegiatan pengabdian masyarakat ini dilaksanakan di bantaran sungai Ciliwung, RT 07 RW 05 Balekambang, Kramat Jati, Jakarta Timur pada bulan Maret hingga Mei 2019 oleh dua dosen dan enam mahasiswa dari Indonesia International Institute for Life Sciences. Tahapan kegiatan yang dilaksanakan meliputi: 1) tahap perencanaan dan persiapan; 2) tahap pelaksanaan; dan 3) tahap evaluasi.

Pada tahap perencanaan dan persiapan, dilakukan pembentukan pengurus pengabdian, perancangan proposal kegiatan, pembuatan materi penyuluhan, serta pembuatan pertanyaan pre-test dan post-test. Selanjutnya, dilakukan koordinasi dengan ketua kelompok IRT untuk penyusunan jadwal acara dan penentuan tempat acara.

Pada tahap pelaksanaan, dilakukan dua kegiatan utama, yaitu penyuluhan mengenai kecacingan serta pelatihan mencuci tangan dengan baik dan benar. Penyuluhan dilakukan dengan cara mempresentasikan materi serta membagikan pamflet edukasi. Materi yang dibawakan mencakup penyebab, dampak, serta cara mencegah dan menanggulangi penyakit kecacingan dengan PHBS. Contoh pencegahan dengan PHBS antara lain (Souisa, et al., 2018; Kartini et al., 2017): menggunakan air bersih, mencuci tangan dengan 
sabun, dan menggunakan jamban sehat. Sementara itu, pelatihan mencuci tangan dilakukan dengan mendemonstrasikan 7 langkah mencuci tangan sesuai dengan yang disarankan oleh WHO (World Health Organization [WHO], 2015).

Tahap evaluasi dilakukan untuk menilai keberhasilan pelaksanaan kegiatan. Penilaian dilakukan dengan memberikan pertanyaan pre-test dan post-test yang harus dijawab oleh peserta penyuluhan sebelum dan sesudah kegiatan. Nilai pretest dan post-test peserta penyuluhan dianalisis menggunakan uji paired $t$-test pada Microsoft Office Excel. Peningkatan nilai post-test dibandingkan nilai pre-test secara signifikan ( $p$-value $<0,05)$ merupakan indikator keberhasilan kegiatan dalam meningkatkan kesadaran masyarakat akan penyakit kecacingan.

\section{HASIL DAN PEMBAHASAN}

\section{Hasil Penyuluhan dan Demonstrasi}

Kegiatan penyuluhan penyakit cacingan serta PHBS dilakukan di Musholla Nurul Haq, Jalan Jembatan I No. 41, RT.7 / RW.5, Balekambang, Kecamatan Kramat Jati, Jakarta Timur pada tanggal 12 April 2019. Peserta penyuluhan terdiri dari 28 IRT anggota kelompok pengajian lokal yang memiliki anak berusia rata-rata 3 sampai 10 tahun (Gambar 1). Anak pada usia pertumbuhan tersebut merupakan kelompok rentan infeksi kecacingan (Lina, 2016).

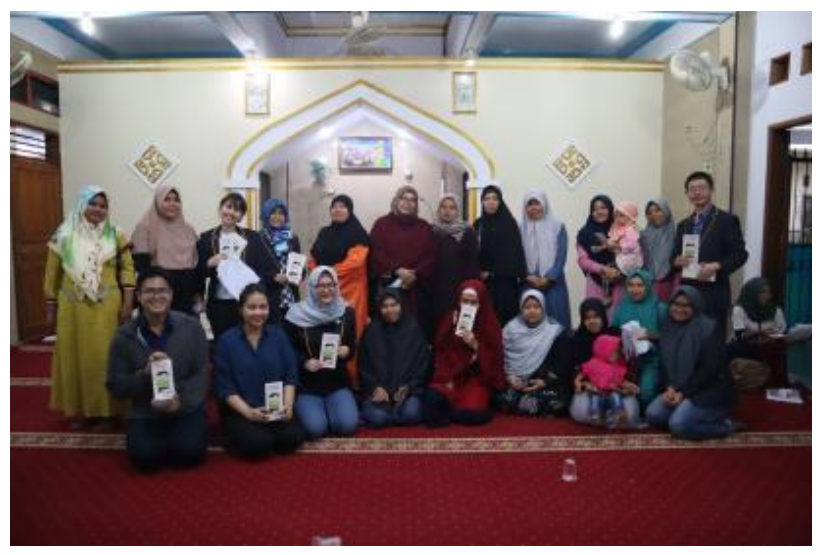

Gambar 1. Foto bersama peserta kegiatan penyuluhan
Kegiatan penyuluhan yang pertama berupa penyampaian materi dalam bentuk presentasi (Gambar 2) dan pamflet (Gambar 3 dan 4). Materi penyuluhan meliputi penjelasan mengenai: 1) definisi kecacingan; 2) jenis cacing yang dapat menyebabkan kecacingan; 3) dampak kecacingan pada kesehatan anak, seperti kekurangan gizi, terhambatnya pertumbuhan anak, dan resiko terburuk dapat menimbulkan kematian; 4) faktor risiko yang dapat menyebabkan infeksi kecacingan pada anak seperti bermain tanpa alas kaki, tidak mencuci tangan dengan baik dan benar, serta mengonsumsi makanan atau air yang masih mentah; 5) gejala kecacingan seperti diare, penurunan berat badan, dan gatal pada area dubur; serta 6) cara mencegah kecacingan melalui PHBS dan pemberian obat cacing setiap 6 bulan sekali (Kartini, 2016; Anwar et al, 2016; Romlah et al., 2016; Juariah, 2017). Pencegahan dan penanggulangan penyakit kecacingan melalui PHBS yang diajarkan meliputi: a) meminum air yang matang karena air mentah merupakan sarana berkembang biaknya cacing; b) menggunakan alas kaki saat bermain di tanah karena cacing dapat masuk ke dalam tubuh melalui kulit (Kartini et al., 2017); c) membuang air besar di jamban, agar tidak mengkontaminasi maupun terkontaminasi air sungai (Kartini et al., 2017); dan d) mencuci tangan dengan baik dan benar.

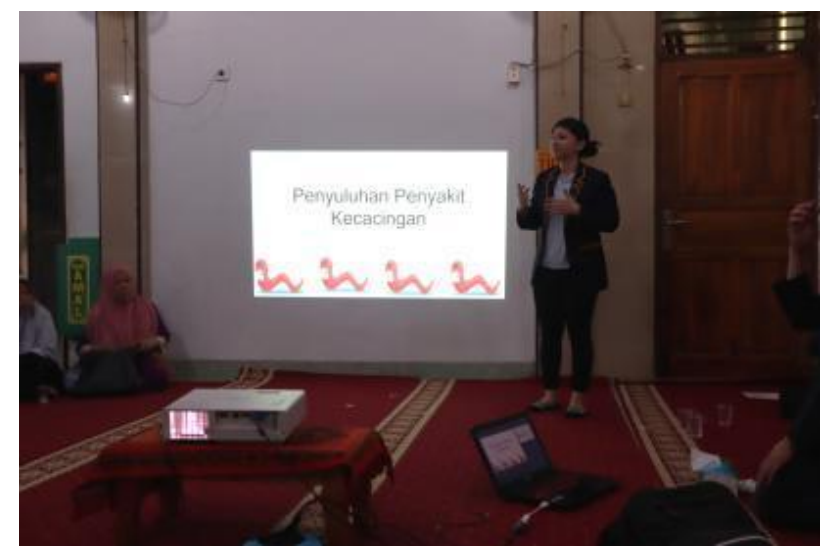

Gambar 2. Presentasi materi mengenai penyakit kecacingan 


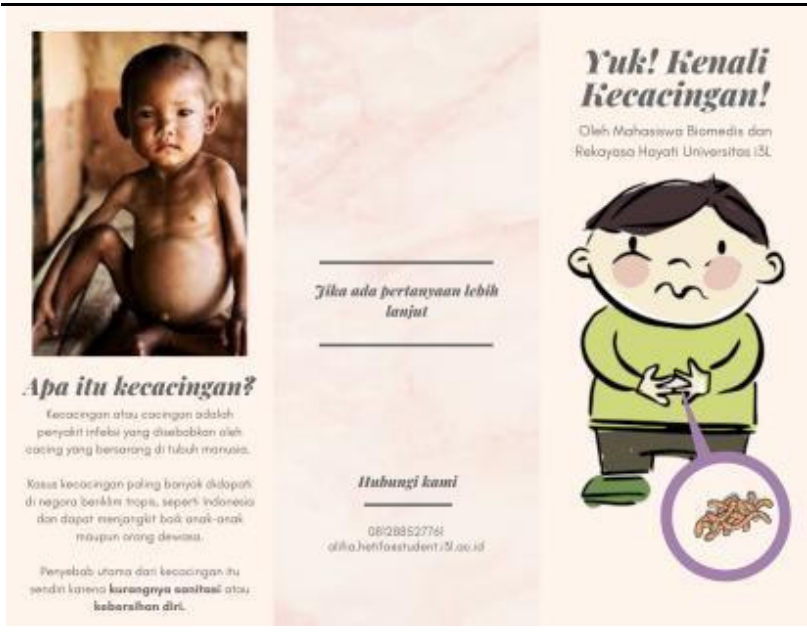

Gambar 3. Pamflet sosialisasi kecacingan (depan)

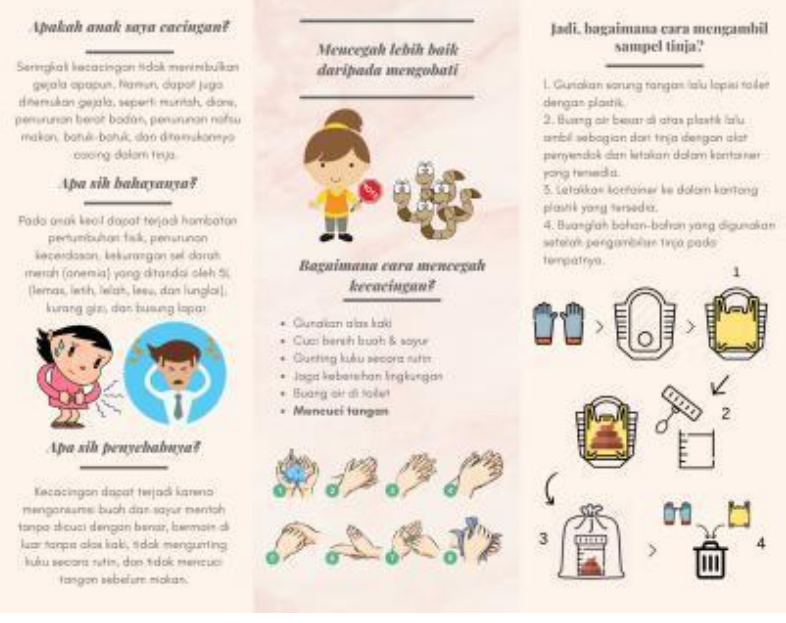

Gambar 4. Pamflet sosialisasi kecacingan (belakang)

Pelatihan mencuci tangan (Gambar 5) dilakukan dengan mendemonstrasikan 7 langkah sesuai anjuran WHO, yaitu: 1) membasahi tangan dengan air mengalir dan menuangkan sabun ke tangan secukupnya lalu menggosokkan kedua telapak tangan; 2) menggosok telapak tangan kanan ke atas punggung telapak tangan kiri dan menjalin jari-jemari pada kedua tangan secara silih berganti; 3) meletakkan telapak tangan kanan ke telapak tangan kiri dengan jari yang terjalin; 4) menautkan jari dari kedua tangan pada posisi saling menggenggam agar sabun mengenai pangkal jari dan kuku; 5) menggenggam ibu jari dan memutar- mutarnya secara bergantian; (6) menggosokkan kuku-kuku ke tengah telapak tangan secara bergantian; 7) membilas tangan dengan air yang mengalir dan mengeringkan tangan dengan tisu atau handuk kering (World Health Organization [WHO], 2015).

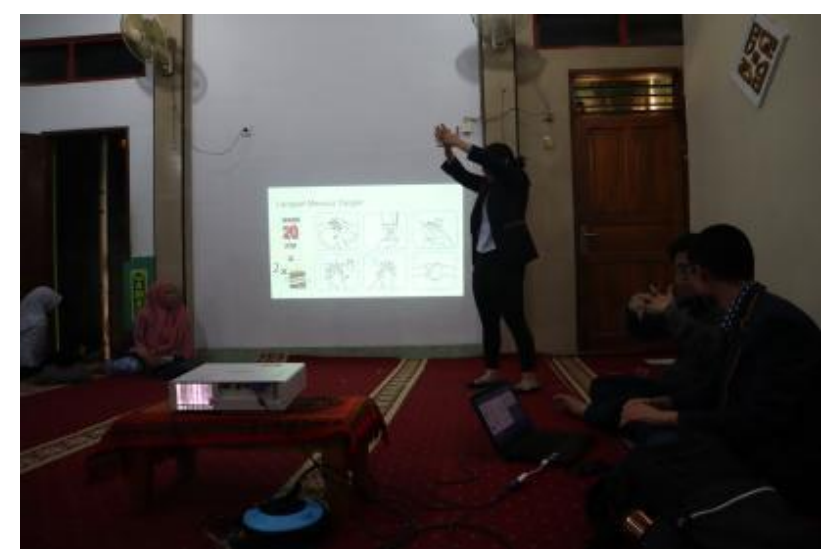

Gambar 5. Demonstrasi langkah mencuci tangan yang benar

\section{Hasil Pre-Test dan Post-Test}

Keberhasilan dari kegiatan ini dalam meningkatkan kesadaran mitra sasaran akan penyakit kecacingan dan PHBS dievaluasi dari nilai pre-test dan post-test. Test terdiri dari 10 butir pertanyaan mengenai definisi, gejala, risiko, pencegahan, dan penanggulangan penyakit kecacingan (Tabel 1).

Tabel 1. Pertanyaan pre-test dan post-test

$$
\text { No. Pertanyaan }
$$

$1 \quad$ Penyakit yang paling sering dianggap sepele?

2 Apa nama cacing yang dapat menginfeksi manusia?

3 Yang bukan merupakan dampak dari kecacingan pada anak adalah?

$4 \quad$ Bagaimana cacing masuk ke dalam tubuh? 
$5 \quad$ Apa saja faktor penyebab kecacingan?

6 Bagaimana cara mengetahui jika seseorang mengalami kecacingan?

$7 \quad$ Bagaimana cara mencegah kecacingan?

8 Bagaimana cara mengobati cacingan pada anak?

$9 \quad$ Hal-hal apa saja yang perlu dihindari dalam pengambilan sampel tinja?

10 Bagaimana cara cuci tangan yang baik?

Dari hasil pre-test dan post-test, didapatkan adanya peningkatan rata-rata nilai yang signifikan setelah kegiatan penyuluhan $(4,96 \pm 2,99)$ dibandingkan sebelum kegiatan $(4,08 \pm 2,56)$ $(p=0,039)$ (Tabel 2). Hal ini menunjukkan adanya peningkatan pengetahuan dan kesadaran IRT sasaran akan penyakit kecacingan dan PHBS

Selain itu, hasil dari post-test sangatlah penting untuk melihat seberapa banyak materi penyuluhan yang telah dapat diterima oleh IRT. Hasil ini menunjukkan bahwa masyarakat sudah dapat mengerti mengenai kecacingan dan PHBS dilihat dari jumlah masyarakat yang mampu menerima materi jauh lebih besar dari pada yang kurang dapat menerima (Tabel 3).

Tabel 2. Hasil uji paired t-test dari pre-test dan post-test $(\mathrm{n}=28)$

\begin{tabular}{ccc}
\hline & Pre-Test & Post-Test \\
\hline Mean \pm SD & $4.08 \pm 2.56$ & $4.96 \pm 2.99$ \\
P-value & \multicolumn{2}{c}{0.039} \\
\hline
\end{tabular}

SD: standard deviation
Tabel 3. Distribusi Penerimaan Materi Setelah Melakukan Post Test

\begin{tabular}{|c|c|c|c|c|}
\hline \multirow[t]{2}{*}{$\underset{*}{\text { Pertanyaan }}$} & \multicolumn{2}{|c|}{ Menerima } & \multicolumn{2}{|c|}{$\begin{array}{c}\text { Tidak } \\
\text { Menerima }\end{array}$} \\
\hline & $\Sigma$ & $\%$ & $\Sigma$ & $\%$ \\
\hline 1 & 25 & 89.3 & 3 & 10.7 \\
\hline 2 & 11 & 39.3 & 17 & 60.7 \\
\hline 3 & 16 & 57.2 & 12 & 42.8 \\
\hline 4 & 18 & 64.3 & 10 & 35.7 \\
\hline 5 & 11 & 39.3 & 17 & 60.7 \\
\hline 6 & 13 & 46.4 & 15 & 53.6 \\
\hline 7 & 15 & 53.6 & 13 & 46.4 \\
\hline 8 & 19 & 67.9 & 9 & 32.1 \\
\hline 9 & 22 & 78.6 & 6 & 21.4 \\
\hline 10 & 15 & 53.6 & 13 & 46.4 \\
\hline
\end{tabular}

Maka demikian, dampak yang dapat diterima oleh masyarakat dengan adanya kegiatan penyuluhan ini adalah meningkatnya kesadaran dan pengetahuan IRT mengenai kecacingan dan pentingnya PHBS dalam mencegah kecacingan. Selain itu, kegiatan ini dapat memberdayakan IRT sehingga IRT dapat turut melanjutkan usaha mengedukasi anak dan keluarga untuk dapat menekan angka infeksi kecacingan di daerah bantaran sungai Ciliwung. 


\section{KESIMPULAN}

Secara keseluruhan, kegiatan PKM yang terdiri dari penyuluhan kecacingan, PHBS, dan demonstrasi cuci tangan yang benar di daerah bantaran sungai Ciliwung, Jakarta Timur, telah berlangsung dengan efektif dan lancar. Hal ini dapat disimpulkan dari hasil evaluasi pre-test dan post-test yang menunjukkan adanya peningkatan pengetahuan dan kesadaran peserta penyuluhan dibandingkan sebelum kegiatan. Kegiatan pengabdian masyarakat ini diharapkan dapat terus berlanjut ke seluruh kalangan masyarakat di sepanjang bantaran sungai Ciliwung. Kerjasama dengan kader posyandu, pihak kelurahan, dan tokoh masyarakat lainnya akan sangat mendukung kegiatan pengabdian masyarakat yang lebih baik dan membantu menurunkan angka penyakit kecacingan pada anak.

\section{UCAPAN TERIMAKASIH}

Terima kasih kami ucapkan kepada Felic Fanusi yang telah membantu kegiatan kami dari sejak persiapan hingga acara penyuluhan. Kami juga berterima kasih kepada Indonesia International Institute for Life Sciences yang sudah memberikan bantuan dana serta kepercayaan kepada kami untuk melakukan kegiatan pengabdian ini.

\section{REFERENSI}

[Kemenkes] Kementerian Kesehatan RI. 2011. Pedoman Pembinaan Perilaku Hidup Bersih dan Sehat (PHBS). Jakarta. Peraturan Menteri Kesehatan.

Anwar, R. Y., Irawati, N., \& Masri, M. (2016). Hubungan antara Higiene Perorangan dengan Infeksi Cacing Usus (Soil Transmitted Helminths) pada Siswa SDN 25 dan 28 Kelurahan Purus, Kota Padang, Sumatera Barat Tahun 2013. Jurnal Kesehatan Andalas, 5(3).

Asosiasi Pengguna Jasa Internet Indonesia (2016). Penetrasi dan Perilaku Pengguna Internet Indonesia, Survey 2016.

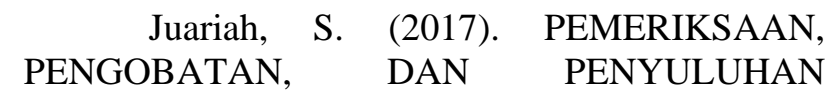

KEBERSIHAN DIRI UNTUK MENCEGAH DAN MENGOBATI KECACINGAN PADA ANAK USIA SEKOLAH GUNA MENINGKATKAN KONSENTRASI BELAJAR PADA ANAK. Jurnal Pengabdian Masyarakat Multidisiplin, 1(1), 32-36.

Kartini, S. (2016). Kejadian Kecacingan pada Siswa Sekolah Dasar Negeri Kecamatan Rumbai Pesisir Pekanbaru. Jurnal Kesehatan Komunitas, 3(2), 53-58.

Kartini, S., Kurniati, I., Jayati, N. S., \& Sumitra, W. (2017). Faktor-faktor yang berhubungan dengan kejadian kecacingan Soil Transmitted Helminths pada anak usia 1-5 tahun di RW 07 Geringging Kecamatan Rumbai Pesisir. JOPS (Journal Of Pharmacy and Science), 1(1), 33-39.

Kementerian Kesehatan Republik Indonesia, 2012. Pedoman Pengendalian Kecacingan. Jakarta: Direktorat Jenderal PP dan PL, p.9.

Kemenkes RI. 2017. Peraturan menteri kesehatan Republik Indonesia no 15 Tahun 2017 tentang Penanggulangan Cacingan. Jakarta:Kemenkes RI.

Kumar, H., Jain, K., \& Jain, R. (2014). A study of prevalence of intestinal worm infestation and efficacy of anthelmintic drugs. medical journal armed forces india, 70(2), 144-148.

Islamudin, R. A., Suwandono, A., Saraswati, L. D., \& Putri, R. K. (2018). The Association Between Soil Transmitted Helminth Infections with Nutritional Status in Children (A Cross Sectional Study in Elementary School, Candi Village, Semarang District, Central Java Province, Indonesia). KnE Life Sciences, 288-295.

Lina, H. P. (2016). Perilaku hidup bersih dan sehat (PHBS) siswa di SDN 42 Korong Gadang Kecamatan Kuranji Padang. Jurnal Promkes: The Indonesian Journal of Health Promotion and Health Education, 4(1), 92-103.

Luo, P., Kang, S., Apip, Zhou, M., Lyu, J., Aisyah, S., Binaya, M., Regmi, R. K., \& Nover, D. (2019). Water quality trend assessment in Jakarta: A rapidly growing Asian megacity. PloS one, 14(7), e0219009. 
Novianty, S., Pasaribu, H. S., \& Pasaribu, A. P. (2018). Faktor Risiko Kejadian Kecacingan pada Anak Usia Pra Sekolah. Journal Of The Indonesian Medical Association, 68(2), 86-92.

Purba, F. D., Hunfeld, J. A., Fitriana, T. S., Iskandarsyah, A., Sadarjoen, S. S., Busschbach, J. J., \& Passchier, J. (2018). Living in uncertainty due to floods and pollution: the health status and quality of life of people living on an unhealthy riverbank. $B M C$ public health, 18(1), 782.

Ribas, A., Jollivet, C., Morand, S., Thongmalayvong, B., Somphavong, S., Siew, C. C., Ting, P. J., Suputtamongkol, S., Saensombath, V., Sanguankiat, S., Tan, B. H., Paboriboune, P., Akkhavong, K., \& Chaisiri, K. (2017). Intestinal Parasitic Infections and Environmental Water Contamination in a Rural Village of Northern Lao PDR. The Korean journal of parasitology, 55(5), 523-532.

Romlah, S., Hadi, H., \& Juffrie, M. (2016). Suplementasi obat cacing, sirup Fe, dan vitamin C meningkatkan kadar hemoglobin dan status gizi balita di Kupang. Jurnal Gizi dan Dietetik Indonesia (Indonesian Journal of Nutrition and Dietetics), l(1), 1-6.
Souisa, G. V., Lawalata, I. V., Titaley, S., \& Talarima, B. Peningkatan Perilaku Hidup Bersih Dan Sehat (PHBS) Pada Pendidik Dan Peserta Didik Di Kecamatan Leihitu Barat Kabupaten Maluku Tengah. JURNAL PENGABDIAN KEPADA MASYARAKAT, 24(3), 747-754.

Suwarni, P., Ilahude, H.D., Harijani. (1991). Kebiasaan penduduk yang ada kaitannya dengan penularan cacing usus sepanjang sungai Ciliwung. Cermin Dunia Kedokteran, 72, 5-7.

Winita, R., \& Mulyati, A. H. (2012). Upaya pemberantasan kecacingan di sekolah dasar. Jurnal Makara, 16(2), 65-71.

World Health Organization [WHO]. (2015). Water sanitation and hygiene for accelerating and sustaining progress on neglected tropical diseases. https://www.who.int/water_sanitation_health/public ations/wash-and-ntd-strategy/en/

World Health Organization [WHO]. (2017). Soil-transmitted Helminth infections. https://www.who.int/news-room/factsheets/detail/soil-transmitted-helminth-infections 